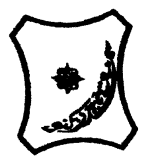

Bayero Journal of Pure and Applied Sciences, 10(2): 52 - 56

Received: July, 2016

Accepted: June, 2017

ISSN $2006-6996$

\title{
EFFECTS OF ORAL ADMINISTRATION OF Momordica charantia ON HAEMATOLOGICAL PARAMETERS OF ADULT ALBINO RATS
}

\author{
*Umar, M.I. \\ Department of Anatomy, Faculty of Basic Medical Sciences, Bayero University Kano \\ mikaumar.muk@gmail.com Tel: +2348034520566
}

\begin{abstract}
The aim of the study was to evaluate the haematological parameters of adult albino rats following oral administration of extract of Momordica charantia. Twenty male adult albino rats were grouped according to their body weights (270 $130 \mathrm{~g})$. The Group A (control) group was administered orally with distilled water daily for six (6) weeks. Group B, C and D were administered orally with $125 \mathrm{mg}$, $250 \mathrm{mg}$ and $500 \mathrm{mg}$ of the extract for six (6) weeks respectively. The rats were humanely sacrificed, blood sample collected was from the heart of the rats, for haematological (red blood cell, white blood cell, hemoglobin, lymphocytes, eosinophil and neutrophils counts) analysis. One-way analysis of variance was used to compare the mean of haematological parameters. It was observed that Momordica charantia elevate the white blood cell count when compared to the control group. It was also observed that the red blood cell count of the groups treated with methanolic extract of Momordica charantia showed no change in value when compared to the control group. There was increase in Iymphocytes and eosinophil count across the groups treated with methanolic extract. Conclusion: The Momordica charantia has potential in elevating some of the haematological parameters of the treated adult albino rats
\end{abstract}

Key wards: Momordica charantia, haematological parameters, albino rats

\section{INTRODUCTION}

Momordica charantia (bitter melon) also called bitter ground, bitter Squash, Karela, Ampalaya, Garahuni, etc. belong to the family cucurbitaceae (Barbieri et al., 1979). The bitter melon has being known for its sugar lowering ability. The use of bitter melon for diabetes has been reported (Tabata, 2012). It was explained recently that it was able to act on a similar way as insulin, with the only difference that insulin stops the use of fats as energy source by inhibiting the release of glucagons and bitter melon inhibits key carbohydrate hydrolyzing enzymes a> a- amylase and a- glucosidase (Mahomoodally et al., 2010). Other clinical conditions where Momordica charantia exhibit some potential include; dyslipidemia, microbial infection and potentially as a cytotoxic agent for certain types of cancer (Pitchakarn, 2012). Another research indicates Momordica charantia extracts modify the immune response in cancer patients via decreased intestinal secretion of interleukin-7, reduced lymphotcyte number and increase T-helper and natural killer cell population (Manabe et al., 2003).

The abuse of Momordica charantia in the northern Nigeria, for the treatments of diabetes mellitus, birth control, cancer, stomach abnormalities and fever, has being going on for many years, and it was observed that people in the rural areas where modern medical facilities cannot satisfy their medical demands are most affected, $80 \%$ of these people rely on the traditional medicine. The abuse of Momordica charantia has gone far and the knowledge of its side effects is not well understood. Since not all contents of the plant's extract usually have medicinal property (Kim et al., 2002). It is then necessary to investigate these side effects in order to provide an important document for the rural settlers and traditional medicine vendors. This would enlighten them on the effects of Momordica charantia. The aim of the study was to evaluate the effect of oral administration of Momordica charantia on the haematological parameters of adult albino rats.

\section{MATERIALS AND METHODS}

Experimental Animals

Male adult albino rats $(n=20)$ with mean body weight of $270 \pm 30 \mathrm{~g}$ were purchased from Animal House of Human Anatomy Department, Ahmadu Bello University, Zaria. The rats were randomly selected and used for this study. They were grouped into a control group A and treatment groups B, C and D, according to their body weights. They were kept in the Animal House of Anatomy Department, Ahmadu Bello University, Zaria for two weeks to acclimatized with the environment according to Grover et al. (2002).

The animals were grouped into a control group $\mathbf{A}$ and the treatment groups B, C and D as follows:

Group A: The control group and has five (5) rats, they were administered orally with distilled water daily for six (6) weeks. 
Group B: $\quad$ The animals in this group were five (5) with average body weights in grammas $260 \pm 20 \mathrm{~g}$ weight. The rats were administered orally with $125 \mathbf{~ m g}$ of the extract for six (6) weeks.

Group C: $\quad$ The rats were also five (5) and their average body weights was $258 \pm 20 \mathrm{~g}$ and were administered orally with $\mathbf{2 5 0} \mathbf{~ m g}$ of the plant extracts for six weeks.

Group D: $\quad$ The rats were five (5), their average weight was $264 \pm 30 \mathrm{~g}$ at the beginning of the study and were administered orally with $\mathbf{5 0 0} \mathbf{~} \mathbf{~ m g}$ of the Momordica charantia extract for six weeks

During this period, the animals were closely monitored and standard environmental conditions plus $(+)$ or minus (-) $25^{\circ} \mathrm{C}$ was maintained, relative humidity of $60 \%$ and 12 hours light and dark cycle were maintained. The animals were properly fed with growers feed from Vital Feed Company. The animals were housed in plastic cages with stainless steel mesh covers, the floors were covered with saw dust which suck away the urine of the rats. This was changed on daily basis.

The Plant

The plant was obtained from some gardeners around Shika Dam, Zaria Local Government (LGA) in Kaduna State, Nigeria on the month of September. The plant was taken to the Herbarium Unit of the Department of Biological Sciences, Ahmadu Bello, University, Zaria, for identification and authentification, The plant was identified as follows: Family name: Cucurbitaceae, Momordica charantia, local name (Hausa): Garahuni, Common name: Balsam pear, Voucher number: 1139. The collection of the plant took about two (2) weeks and was taken in the early morning and after sun set as was suggested by Sofowora, (2012).

The leaves and stem of the plant were carefully packed into a well ventilated room and spread sparsely for shade drying. Every two (2) days the spread plant was checked and overturned. This process was run for two (2) weeks for the plant to dry. The leaves and stem of the plant were parked and crushed into powdered by means of wooden mortar and pestle. The powdered form was weighed to be $2.6 \mathrm{~kg}$ which was assumed to be enough for the extraction procedures.

\section{Extraction of Momordica charantia}

Maceration method was used for the extraction, $500 \mathrm{~g}$ of the powder of the plant was taken and placed into a separating funnel with a clean cotton wool placed at the narrowed part of the funnel to block the passage of the plant into the collecting beaker plate I. At first, 2 liters of cool methanol was poured onto the $500 \mathrm{~g}$ in the funnel and allowed to drain for 12 hours plate I. The powder was observed to be greenish which suggested that there were more of plants' constituents remaining, hence the need to put more methanol plate II. The extraction continued for another 12 hours until the powder became pale yellowish. A total of 5.5 liters of methanol was used for the methanolic extraction.

The filtrate was collected in a collecting beaker and poured into evaporating dishes which were on water bath machines at $45^{\circ} \mathrm{C}$. The filtrate was evaporated and dried for 8 hours. The filtrate was then collected in a glass bottle and weighted.

\section{Phytochemical Screening of Momordica charantia}

Basic phytochemical screening consists of performing simple chemical tests to detect the presence of alkaloids, tannins, saponins, anthraquinones, cardenolides in the plant's extract. Simple, standard chemical tests have been devised for this study as laid down by Evans (1996) and adopted by Abdullahi et al., 2003

\section{Acute Toxicity Study}

The limit test of the extract of Momordica charantia was conducted at as high dose as $1000 \mathrm{mg} / \mathrm{kg}$ body weight and was relatively found to be safe within 48 hours observation period following oral administration of a single dose to the adult albino rat. $\mathrm{LD}_{50}$ was determined to be $1855 \mathrm{mg}$ (Evans and Bicks 1995; Abdullahi et al., 2003). The choice of the dosages was based on the fact that at high dose of $1855 \mathrm{mg}$ of the methanolic extract of Momordica charantia, there was no toxicity on treated rats for pilot study was observed. Therefore the animals were exposed to the selected dosages for long period of six (6) weeks for chronic toxicity study as was suggested by Grover and Yadav (2004).

\section{Administration of the Extract to the Animals}

The animals were weighed just before the commencement of the extract administration. The administration of the extract was done for the period of six (6) weeks. The extract of Momordica charantia was measured by means of electronic measuring machine which measures in milligram $(\mathrm{mg})$. The measured extracts were then transferred to well labelled small size plastic bottles. The bottles where labelled $125 \mathrm{mg}, 250 \mathrm{mg}$ and $500 \mathrm{mg}$ of Momordica charantia. The corresponding weights were placed in each bottle with same label.

The extract of Momordica charantia is water soluble and was administered by oral route. Robber-caped needles were used to administer the extracts. The extracts were dissolved in warm distilled water by vigorous shaking, to facilitate dissolution of the extract. The content was immediately taken and administered to the rats. The period of extract administration took six (6) weeks and was done at a fixed time daily 9:00 am as was done by Atama and Idu (2007).

\section{Collection of Blood Sample}

The blood samples were collected from the rats by cardiac puncture, while the rats were under anaesthesia. The rats were anaesthesized with chloroform. The thorax was carefully opened with sharp scissors. The blood was carefully taken by cardiac puncture through the anterior surface of the heart, using sterilized syringes. The blood was divided into two (2) parts; volume of blood taken was about $5 \mathrm{ml}$ to $7 \mathrm{ml}$ and was immediately transferred to the collecting bottles. 
The blood taken from each rat and was placed in $10 \%$ EDTA bottle to prevent clotting of blood. hematological analysis of red blood cell (RBC), white blood cell (WBC), hemoglobin, lymphocytes, eosinophil and neutrophils counts was carried out as according to Sujathan et al. (2011).

\section{Statistical Analysis}

One-way analysis of variance (ANOVA) was used to compare data both between the groups and Holm Sidak multiple comparison post hoc tests was used. It best compares the level of significance between the control and the test groups. All data were expressed as mean \pm SEM. The data obtained were analysed with statistical package for social science (SPSS) software version $20 . \mathrm{P}<0.05$ were considered to be significant.

\section{RESULTS}

The results of white blood cell (WBC) count in this study showed that the group treated with the methanolic extract of Momordica charantia had elevated value of the WBC count when compared to the control group (Figure1). It was observed that the red blood cell (RBC) count of the groups treated with methanolic extract of Momordica charantia showed no change in value when compared to the control group. The statistical analyses also showed no significant difference between the treated and the control group (Figure 2).

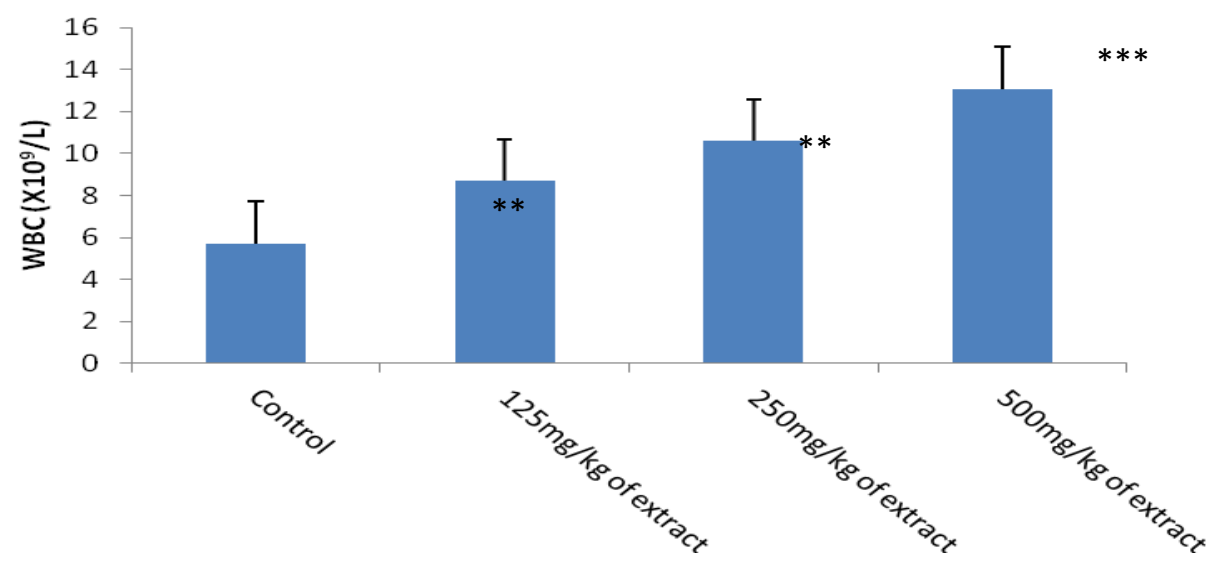

Figure 1: The effect of methanolic extract of Momordica charantia on white

blood cell count in albino rats. ( $* * \mathrm{P}=0.027, * * * \mathrm{P}=0.014, \mathrm{n}=5)$.

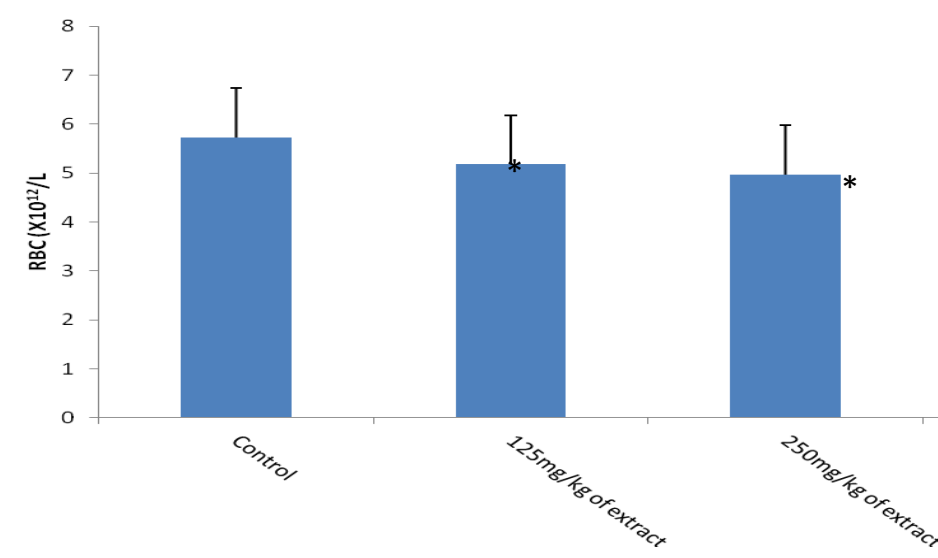

Figure 2: The effect of methanolic extract of Momordica charantia on red blood $(* \mathrm{P}=0.038, \quad \mathrm{n}=5)$
This study also revealed that there was no change in hemoglobin values across the groups treated with methanolic extract of Momordica charantia when compared to the control group (Figure 3). On the other hand, there was increase in lymphocytes count across the groups treated with methanolic extract of Momordica charantia when compared to the control group (Figure 4). There was increase in eosinophil values across the groups treated with the methanolic extract of Momordica charantia when compared to the control group. The statistical analyses indicated that there was significance different between the treated groups and the control groups (Figure 5). 
Bajopas Volume 10 Number 2 December, 2017

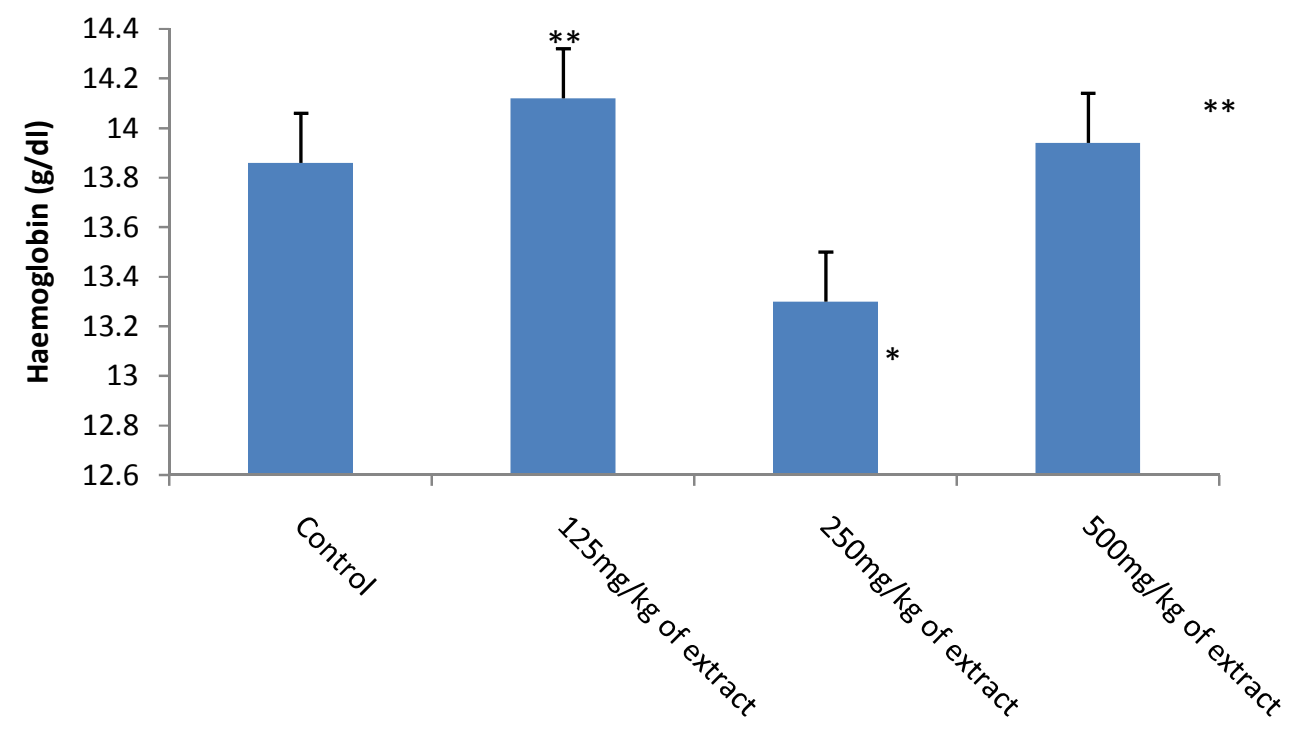

Figure 3: The effect of methanolic extract of Momordica charantia on haemoglobin concentration in albino rats. $(* * \mathrm{P}=0.866, * \mathrm{P}=0.169 \mathrm{n}=5)$

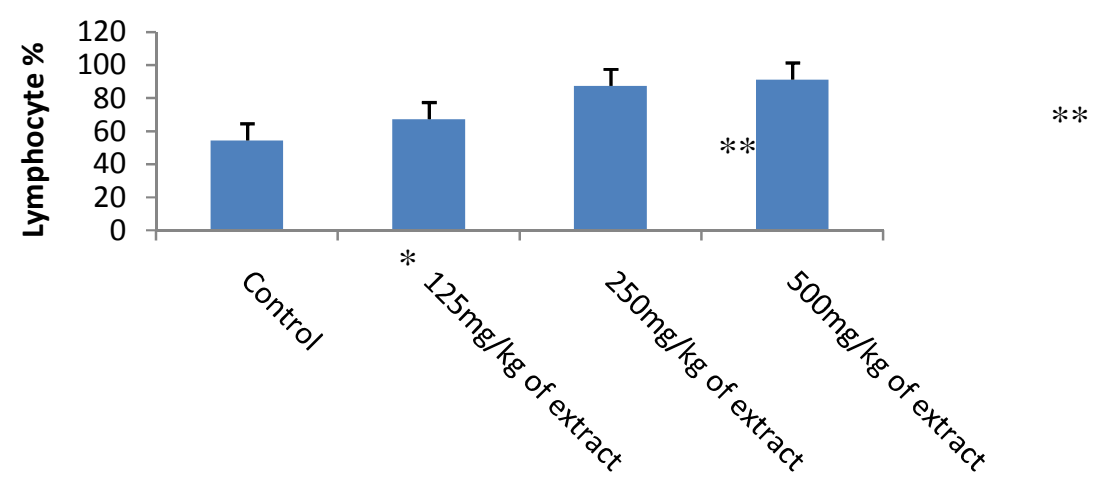

Figure 4.4: The effect of methanolic extract of Momordica charantia on lymphocyte count in albino rats. $* * \mathrm{P}=0.024, * \mathrm{P}=0.017 \quad \mathrm{n}=5$

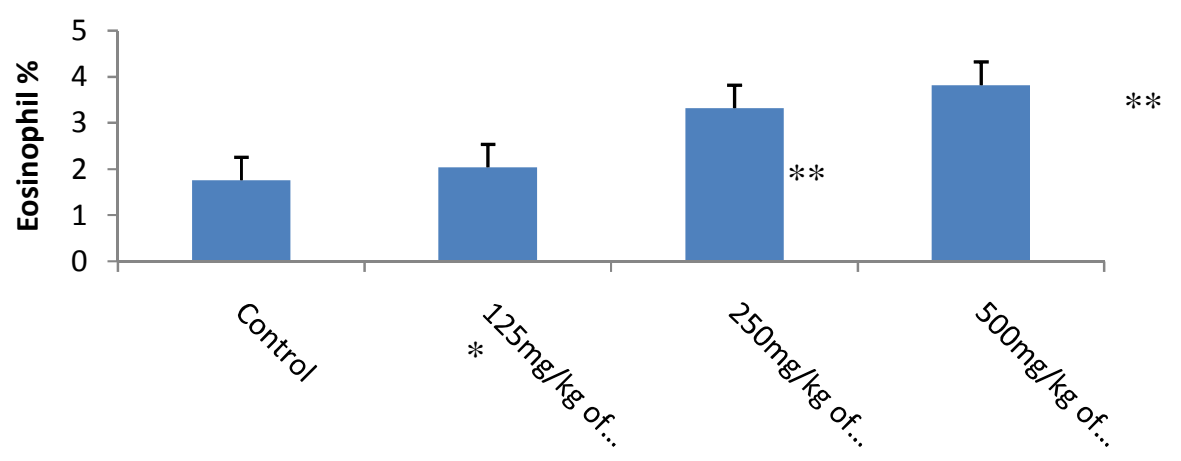

Figure 5: The effect of methanolic extract of Momordica charantia on eosinophil count in albino rats. ( $* * \mathrm{P}=0.047, * \mathrm{P}=0.031, \mathrm{n}=5$ ) 


\section{DISCUSSION}

In this study, it was observed that the WBCs count had elevated levels across the treated groups. The elevated levels $(P<0.05)$ of white blood cells (WBCs) in many conditions indicate infection, stress, inflammation, trauma, allergy or certain disease in an organ, tissue or the whole organism (Shcrier, 2010). The methanolic extract of Momordica charantia at higher dose in this study might have caused some toxic effects on the body system of the treated rats, and consequently, the elevation of white blood cells (WBCs). This is because the white blood cells (WBC) are known to play an important role in animal body's immune system. They search the blood for invading viruses, bacteria, and fungi. When foreign virus or bacteria enters the blood, the white blood cells (WBCs) or leukocytes recognize and destroy the invading particle before it causes disease (Shcrier, 2007).

The red blood cells (RBCs) count in this study indicates no significant difference between the treated and the control groups. It is believed that when red blood cells (RBCs) count drops to lower than the normal range, it indicates anemia. Anemia has many causes including, low level of certain vitamins or iron, blood loss or due to an underlying condition (Sachs, 2007).

In this study, the percentage of lymphocyte was found to be elevated. It is believed that when there is increasing antigen in the body, the immune systems trigger the release of lymphocytes and elevate the

\section{REFERENCES}

Abdullahi, M., Muhammad, G., and Abdulkadir, N.U. (2003). Medicinal and economic plants of Nupeland, Jube Evans Books and Publisher, ISBN 978-33921-9-0, pg 95.

Anderson, R.J., Gabow, P.A. and Gross, P.A. (2004). Urinary chloride concentration in acute renal failure. Miner Electrolyte Metabolism, 10:92-97.

Atama, J.E and Idu, M. (2007). Histopathologic effects of mathanolic extract of Momordica charantia leaves on the liver of Wister rats. Trends in Medical Research Journal, 2(4): 176-184.

Barbieri, L., Lorenzoni, E. and Stirpe, F. (1979). Inhibition of protein synthesis in vitro by lectin from Momordica charantia. Journal of Ethnopharmacology 18(2): 633-635.

Evans G., and Bicks R.L (1996). Simplified method of phytochemical analysis. Journal of medical laboratory technology. 10; 7-13.

Grover, J.K., and Yadav, S.P. (2004), Pharmacological actions and potential uses of Momordica charantia: a review. Journal of Ethnopharmacology, 93(1): 123-132.

Grover, J.K., Yadav, S. P and Vats, V. (2002). Medicinal plants in India with anti-diabetic potential. Journal of Ethnopharmocology, 81:81-100.

Khan, M.R. and Omoloso, A.D. (2008). Momordica charantia and allium sativum: board spectrum antibacterial activity. Korean Journal Pharmacology. 29:155-158.

Mahomoodally, M.F., Subratty, A.H., Gurib-Fakim, A., Choudhary, M.I. and Nahar, K.S. (2010). Traditional medicinal herbs and food plants have the potentials to inhibit key carbohydrate hydronizing enzymes in vitro and reduce post prandial blood glucose peaks in vivo. Journal of Traditional Medicine, 93: 1010110 number of lymphocytes in the body (Pepin et al., 2007). Lymphocytes are one of the main types of immune cells. They are divided into B-lymphocyte and T-lymphocytes. B-lymphocyte produces antibodies proteins (gamma globulins) that recognize foreign substances (antigen) and attach themselves to them. They are programmed to make one specific antibody. When B-lymphocytes attach to an antigen (foreign body), they mark it for destruction and become powerless. T-lymphocytes then attacked the target cells and destroy it. Other T-lymphocytes are programmed to be able to destroy targeted cells on direct contact (Pepin et al., 2007).

In this study neutrophil levels were found to be elevated. Neutrophils are a type of white blood cell that body uses to fight infections. High neutrophil levels often result from cases of infection, but other medical conditions and certain drugs can raise their levels as well. For example, physical and mental stress can also cause increase in neutrophil levels. High neutrophil levels do not usually indicate a serious immune problem and are considered to be harmless. In most cases, the levels return to normal after sometimes (Anderson et al., 2004).

In conclusion, the oral administration of extract of Momordica charantia has produced some negative effects on haematology parameters of adult albino rats. The extract causes increase in level of white blood cells, lymphocytes eosinophils and neutrophils in a dose dependant manner.

Conflict of Interest: None

Manabe, M., Takenaka, R., Nakasa, T. and Okinaka, O. (2003). Induction of anti-inflammatory responses by dietary Momordica charantia L. (bitter gourd). Bioscience Biotechnology and Biochemistry Journal, 67:2512-2517.

Pepin, M.N., Bouchard, J., Legault, L. and Ethier, J. (2007). Diagnostic performance of fractional excretion of urea and fractional excretion of sodium in the evaluations of patients with acute kidney injury with or without diuretic treatment. American Journal of Kidney Disease, 50:566-573.

Pitchakarn, P. (2012). Kuguacin J, a triterpeniod from Momordica charantia leaf modulates the progression of androgen-independent human prostate cancer cell line, PC3.Food Chemistry Toxicology, 50(3-4): 840-7.

Sachs, L. (2007). The molecular control of blood cell development. American Journal of Science, 238:1374

Schrier, R.W. (2007). Decreased effective blood volume in edematous disorders: What does this mean? Journal of American Society of Nephrologists, 18:2028-2031.

Schrier, R.W. (2010). Fluid administration in critically ill patients with acute kidney injury. Clinical Journal of American Society of Nephrologists, 5:733-739.

Sofowara A. (2012). Medicinal plants and traditional medicine in Africa, (Rep. and updated version, 2012)

Sujathan, K., Karamala, S.L., Anjaneyulu, H.Y., Chandra, S., Rao T.S., Sreeni, V.D. and Amravathi, P.P. (2011). Haematobiochemical changes of lead poisoning and amelioration with ocimum sanction in Wistar albino rats. Veterinary World, 4 (6): 260-263.

Tabata, K. (2012). Kuguaglycoside C. a constituent of Momordica charantia, induces caspase-independent cell death of neuroblastoma cells. Cancer Science. 103(12): 2153-8. 